\title{
BACTERIAS HALOTOLERANTES PRODUCTORAS DE HIDROLASAS AISLADAS DE AGUAS TERMALES DE TARAPOTO - PERU
}

\author{
Halotolerant bacteria producing hydrolytic enzymes isolated from hot springs from Tarapoto - Peru \\ Jackelyn E Borja, Amparo I Zavaleta, Víctor Izaguirre \\ Laboratorio de Biología Molecular de la Facultad de Farmacia y Bioquímica. Universidad Nacional Mayor de San Marcos. \\ Lima, Perú
}

\section{RESUMEN}

El objetivo de este estudio fue caracterizar bacterias halotolerantes productoras de hidrolasas de interés biotecnológico aisladas de aguas termales de Tarapoto. Para ello, se recolectaron muestras de agua y se sembraron en agar tripticasa de soya conteniendo cloruro de sodio $5 \%$ a $37^{\circ} \mathrm{C}$ por $24 \mathrm{~h}$. Se seleccionaron 14 bacterias por presentar colonias de diferente tamaño, color y consistencia, luego se determinaron sus características morfológicas, fisiológicas y capacidad hidrolítica a tween 8o, almidón, gelatina, carboximetilcelulosa y lactosa. Los 14 aislados se agruparon según el perfil de hidrólisis de los sustratos antes descritos en los siguientes grupos: I (almidón), II (lactosa), III (tween 8 o y gelatina), IV (tween 80 y almidón), V (almidón, gelatina y lactosa), VI (tween 8o, almidón y gelatina) correspondiendo en número de bacterias a 1, 1, 1, 5, 1, 5; respectivamente. El 86\% (12/14) de los aislados hidrolizó más de dos sustratos, pero ninguno carboximetilcelulosa; el $93 \%$ (13/14) fueron bacilos, crecieron optimamente entre 30 y $40^{\circ} \mathrm{C}$ a pH entre 5,o y 8,o, todos formaron colonias de consistencia gomosa. Las características culturales de los aislados y los perfiles de hidrólisis indican que al menos existen 6 especies o cepas bacterianas productoras de enzimas hidrolíticas con gran potencial industrial.

Palabras clave: bacterias halotolerantes, aguas termales, enzimas hidrolíticas, Tarapoto.

\section{SUMMARY}

The aim of this study was to characterize halotolerant bacteria producing hydrolases of biotechnological interest isolated from hot springs from Tarapoto. For that, water samples were collected and plated on trypticase soy agar containing $5 \%$ sodium chloride at $37^{\circ} \mathrm{C}$ for $24 \mathrm{~h}$. 14 aerobic bacterial isolates were selected to show colonies of different size, colour and consistency, then morphological and physiological properties and hydrolytic capacity to tween 8o, starch, gelatin, carboximetilcellulose, lactose were determined. The 14 isolates were grouped according to substrate hydrolyzation profiles in groups: I (starch), II (lactose), III (Tween 80 and gelatin), IV (tween 80 and starch ), V (starch, gelatin, lactose), VI (tween 80 , starch and gelatin) corresponding in number of bacteria $1 ; 1 ; 1 ; 5 ; 1,5$; respectively. $86 \%(12 / 14)$ of isolates hydrolyzed more than one substrate, but none carboxymethylcellulose, $93 \%$ (13/14) were bacilli, grew optimally between 30 and $40^{\circ} \mathrm{C}$ at $\mathrm{pH}$ between 5 and 8 , all formed colonies of rubbery consistency. The cultural characteristics of the isolates and the hydrolyzed substrate profiles indicate that there are at least 6 species or bacterial strains producing hydrolytic ezymes of great industrial potential.

Keywords: halotolerant bacteria, hot spring, hydrolytic enzymes, Tarapoto.

\section{INTRODUCCIÓN}

os hábitats extremos son fuentes de microorganismos con características especiales en la producción de metabolitos y enzimas. En los últimos años, el interés por el estudio de sus enzimas se ha incrementado debido a sus propiedades catalíticas en condiciones exigentes y por su potencial aplicación en la elaboración de productos alimenticios y dietéticos, biosíntesis de nuevos productos, formulación de detergentes, así como síntesis de fármacos enantioméricamente puros, biodegradación de residuos tóxicos y contaminantes industriales, entre otros ${ }^{(1-4)}$.
Las aguas termales son ambientes extremos, ya que tienen altas temperaturas y elevadas concentraciones iónicas, condiciones desfavorables para la vida de muchos seres. Sin embargo, se ha descrito que este nicho ecológico contiene una microbiota autóctona dependiente de las propiedades fisicoquímicas del agua ${ }^{(5,6)}$. Además, en base a sus requerimientos nutricionales predominan diversas bacterias heterótrofas y oligotróficas, tales como: Pseudomonas, Bacillus, Staphylococcus, Enterobacter, Acinetobacter con escasa demanda de carbono y nitrógeno. La mayoría de estas bacterias son aerobias o anaerobias facultativas, de tamaño pequeño, móviles y con pigmentos. Generalmente, las bacterias 
heterótrofas no suelen fermentar los azúcares pero son proteolíticas, amilolíticas y en menor número celulolíticas ${ }^{(7)}$.

Actualmente, las industrias requieren procesos tecnológicos eficientes y limpios que soporten temperaturas y $\mathrm{pH}$ extremos, es por ello que, el aislamiento de nuevos microorganismos de estos ambientes o sus enzimas constituye una alternativa para la obtención de bacterias con características particulares para atender la creciente demanda del mercado biotecnológico ${ }^{(8,9)}$.

Es así que el objetivo de este estudio fue aislar y caracterizar bacterias productoras de enzimas hidrolíticas extracelulares a partir de aguas termales de Tarapoto, ciudad tropical ubicada al nororiente del Perú aproximadamente a $300 \mathrm{msnm}$.

\section{MATERIALES Y MÉTODOS}

Aislamiento de microorganismos. Se recolectaron 10 muestras de aguas termales de Tarapoto, se transportaron al laboratorio y se guardaron en refrigeración. Con las muestras se realizaron diluciones seriadas al décimo desde $10^{-2}$ hasta $10^{-12}$, utilizando como diluyente cloruro de sodio $5 \%$. Luego, se sembraron alícuotas de $0,1 \mathrm{~mL}$ de las diluciones en agar tripticasa de soya conteniendo cloruro de sodio $5 \%$ a $37^{\circ} \mathrm{C}$ durante 24 horas. Los aislados fueron seleccionados según tamaño, color y consistencia de las colonias. Para la determinación del tipo de pared celular y forma bacteriana se utilizaron cultivos frescos de $14 \mathrm{~h}$.

Pruebas fisiológicas. Los aislados se inocularon en caldo tripticasa de soya conteniendo cloruro de sodio o, 5, 10, 15y $20 \%$. Luego, los cultivos bacterianos se incubaron a $37^{\circ} \mathrm{C}$ por $24 \mathrm{~h}$, la densidad celular se determinó por espectrofotometría a $600 \eta \mathrm{m}$. Para determinar el $\mathrm{pH}$ óptimo de crecimiento se utilizó el caldo tripticasa de soya cuyo $\mathrm{pH}$ fue ajustado a 6,0; 7,0 y 8,0 con $\mathrm{NaOH}{ }_{1} \mathrm{~N}$ o $\mathrm{HCl}_{1} \mathrm{~N}$. Del mismo modo, se determinó la temperatura óptima cultivándolos a 20, 30, 37,40 y $50^{\circ} \mathrm{C}$.

\section{Actividad hidrolítica a diversos sustratos}

Almidón. Se utilizó agar almidón (DIFCO), las placas se incubaron a $37^{\circ} \mathrm{C}$ durante 72 horas. Luego, se añadieron $10 \mathrm{~mL}$ de lugol sobre cada placa, considerándose reacción positiva cuando se observó la formación de halos claros alrededor de las colonias productoras de amilasas.

Tween 8o. Los aislados se sembraron en agar extracto de levadura $0,2 \%$ conteniendo tween 80 al $1 \%$. Las placas se incubaron a $37{ }^{\circ} \mathrm{C}$ durante 72 horas, la hidrólisis se determinó según lo descrito por SánchezPorro y col ${ }^{(10)}$.

Gelatina. Los aislados se sembraron en agar gelatina $5 \%$ y se incubaron a $37^{\circ} \mathrm{C}$ por 48 horas. Luego, los cultivos se colocaron a $4{ }^{\circ} \mathrm{C}$ por 20 minutos. La actividad proteolítica se evidenció por licuefacción del medio a temperatura ambiente.

Lactosa. Se centrifugó o, 2 mL de cada cultivo bacteriano de 18 horas, las células se resuspendieron en o,2 mL de buffer fosfato salino conteniendo orto-nitrofenilgalactopiranósido y se incubó a $37^{\circ} \mathrm{C}$ durante 24 horas, la coloración amarilla indicó reacción positiva.

Carboximetilcelulosa.Lasbacteriassecultivaronenagar tripticasa de soya conteniendo carboximetilcelulosa $1 \%$, se incubaron a $37^{\circ} \mathrm{C}$ por 72 horas. Luego se le adicionaron $4 \mathrm{~mL}$ de rojo de Congo o,5\%; la actividad celulolítica se evidencio por la presencia de halos claros alrededor de la colonia.

\section{RESULTADOS}

Se aislaron 14 bacterias halotolerantes con características diferentes en la formación de colonias en lo referente a consistencia, colory tamaño. Todos las colonias presentaron consistencia gomosa (figura 1), de color crema, a excepción de los aislados TL16 y TJB que fueron de color blanco y naranja, respectivamente. Mediante tinción Gram y microscopía óptica se determinó que el $79 \%$ (11/14) de los aislados fueron

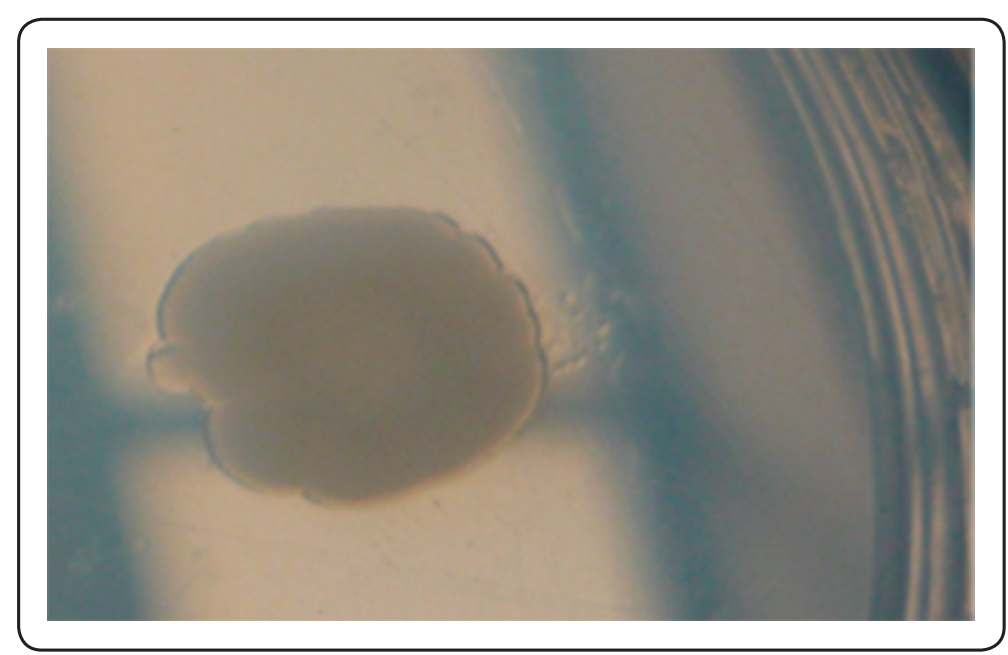

Figura 1. Colonia del aislado TL8 crecido en agar tripticasa de soya. 


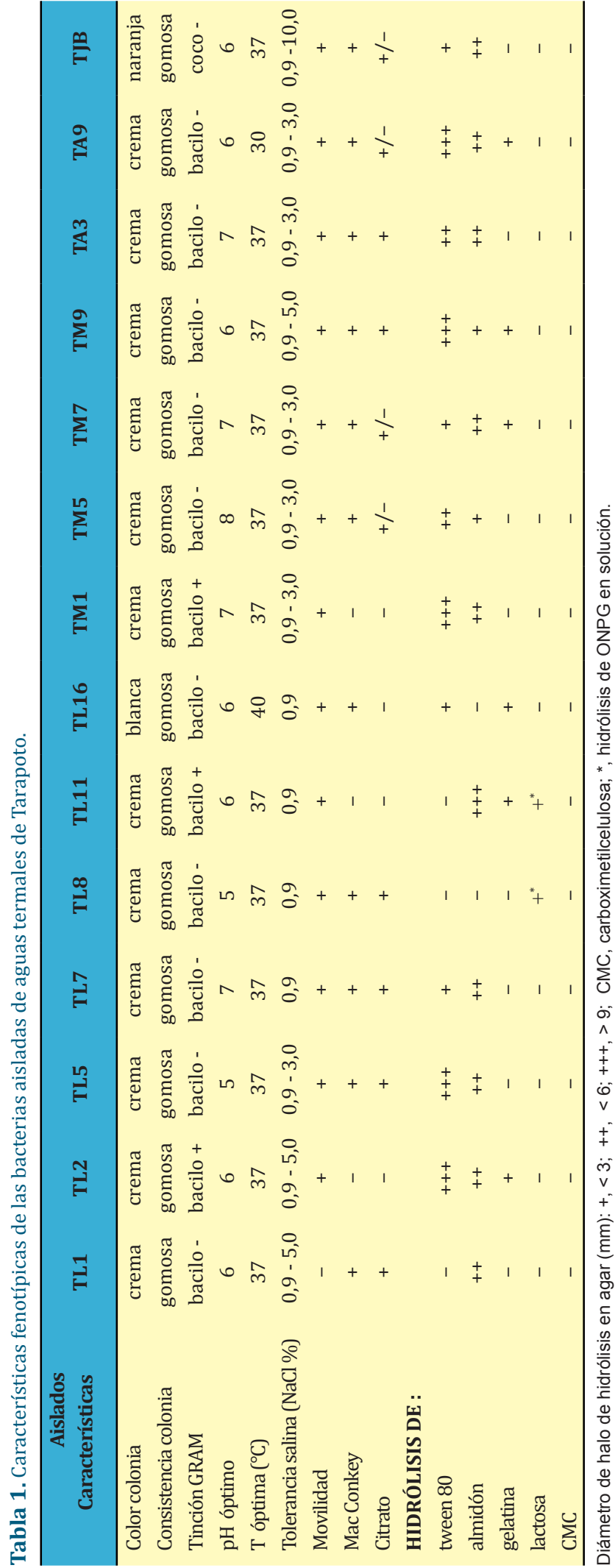

bacilos Gram negativos, siendo los aislados TL2, TL11, TMı bacilos Gram positivos y TJB cocos Gram negativos (tabla 1).

Los aislados bacterianos crecieron en medios de cultivo conteniendo cloruro de sodio entre o, 9 y 10,0\%; el $21 \%(3 / 14)$ toleró hasta $5 \%$ de sal; sin embargo, el aislado TJB creció hasta 10\%. El 86\% (12/14) de bacterias crecieron óptimamente a $37^{\circ} \mathrm{C}$, a excepción de los aislados TJ9 y TL16 que crecieron a 30 y 40 ${ }^{\circ} \mathrm{C}$, respectivamente. El 50\% (7/14) de las bacterias crecieron a $\mathrm{pH}$ 6,o; el aislado $\mathrm{TM}_{5}$ a $\mathrm{pH}$ 8,o; el $93 \%$ (13/14) de los microrganismos son móviles a excepción de TL1; el 79\% (11/14) de las bacterias crecieron en agar Mac Conkey (tabla 1).

Con respecto a la capacidad hidrolítica de las bacterias halotolerantes, éstas degradan de uno a tres sustratos generando perfiles de hidrólisis diferentes denominados grupos. Así, los grupos y sustratos son: I (almidón), II (lactosa), III (tween 8o y gelatina), IV (tween 80 y almidón), V(almidón, gelatina y lactosa), VI (tween 8o, almidón y gelatina), cada grupo contiene, en número $1,1,1,5,1$ y 5 cepas bacterianas, respectivamente; el 86\% (12/14) de bacterias hidrolizan de 2 a 3 sustratos; el almidón, tween 80 y gelatina son hidrolizados por el 86,79 y $43 \%$ de las bacterias (figura 2). El almidón y la lactosa son hidrolizados por los aislados TL1 y TL8 (tabla 2).

\section{DISCUSIÓN}

En aguas termales existen diversos microorganismos que dependen de las características fisicoquímicas del agua, suelo, clima y región geográfica ${ }^{(7)}$. Los microorganismos aislados crecieron en un rango de salinidad entre 0,9 a $10,0 \%$, de 30 a $40^{\circ} \mathrm{C}$ y a pH entre 5,o a 8,0; en base a ello, y desde un punto de vista fisiológico se puede inferir que las bacterias aisladas son halotolerantes ${ }^{(9)}$.

En la producción a gran escala de enzimas y metabolitos, la halotolerancia es una característica fisiológica importante en un proceso fermentativo industrial dadoquepermitedisminuirlacontaminación microbiana.

El predominio de bacterias Gram negativas en aguas termales es común, la mayoría de especies descritas son bacilos móviles ${ }^{(6)}$. Así, el 93 y $79 \%$ de las bacterias aisladas de los ambientes termales de Tarapoto son móviles y bacilos Gram negativos. Esta última característica se evidenció por el crecimiento bacteriano en el medio Mac Conkey, el cual permite el aislamiento de bacilos Gram negativos de fácil 


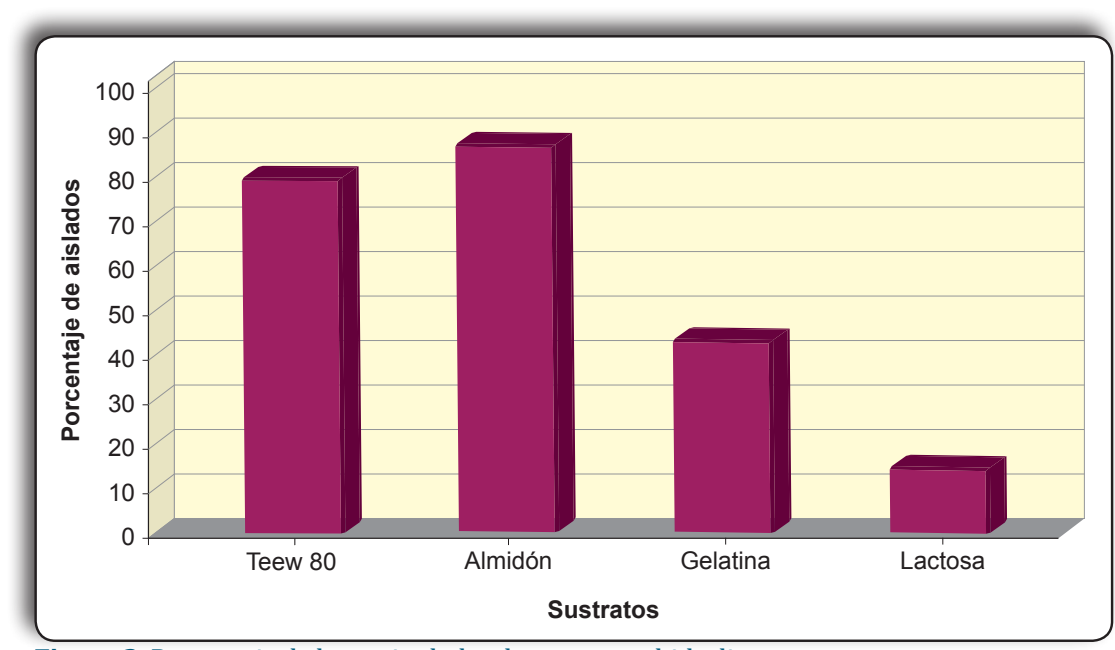

Figura 2. Porcentaje de bacterias halotolerantes que hidrolizan sustratos.

desarrollo, aerobios y anaerobios facultativos ${ }^{(11)}$ (tabla 1). En aguas termales de zonas geográficas diversas se han descrito bacterias halotolerantes moderadas, de forma bacilar, con actividad aminolítica en la misma proporción (7). Así, Leveque y col. aislaron microrganismos amilolíticos termoestables que luego de estudios fenotípicos y genotípicos demostraron ser $B$. subtilis, B. amyloliquefaciens y B. licheniformis; asimismo, concluyeron que las amilasas termoestables ofrecen mayores ventajas con respecto al uso de enzimas aisladas de microorganismos mesófilos debido a que el almidón, al ser transformado, es más soluble a altas temperaturas, lo cual hace preferible la implementación de procesos termófilos ${ }^{(12,13)}$.

La presencia de microorganismos con actividad amilolítica y proteolítica en ambientes termales es alta, por ello el 86 y $43 \%$ de los aislados degradaron almidón y gelatina, pero con diferentes grados de actividad valorados en el tamaño del halo de hidrólisis (tabla 1). Similares resultados fueron descritos por Lee y col.,

Tabla 2. Características fenotípicas de las bacterias aisladas de aguas termales de Tarapoto.

\begin{tabular}{cccc}
\hline $\begin{array}{c}\text { Código de } \\
\text { aislado }\end{array}$ & $\begin{array}{c}\text { Aislados } \\
\text { (N) }\end{array}$ & $\begin{array}{c}\text { Sustrato } \\
\text { hidrolizado }\end{array}$ & $\begin{array}{c}\text { Perfil de } \\
\text { hidrólisis }\end{array}$ \\
\hline TL1 & 1 & Almidón & I \\
TL8 & 1 & $\begin{array}{c}\text { Lactosa } \\
\text { Gelatina, } \\
\text { Tween 80 } \\
\text { TL16 }\end{array}$ & Almidón, \\
TL5, TL7, TM5, & 5 & $\begin{array}{c}\text { Tween 80 } \\
\text { TA3, TJB }\end{array}$ & IV \\
TL11 & 1 & $\begin{array}{c}\text { glmidón, } \\
\text { lactosana } \\
\text { Almidón, } \\
\text { gelatina, } \\
\text { Tween 80 }\end{array}$ & V \\
$\begin{array}{c}\text { TL2, TM1, TM7, } \\
\text { TM9, TA9 }\end{array}$ & 5 & & \\
\hline
\end{tabular}

quienes aislaron de aguas tropicales 56 y $36 \%$ de microorganismos con actividad amilolítica y proteolítica, respectivamente. En su mayoría, los miembros del género Pseudoalteromonas, presentaron actividades de amilasa y proteasa ${ }^{(14,15)}$.

El $79 \%$ de bacterias degradan Tween 8o, la hidrólisis de este sustrato indica actividad esterásica. $\mathrm{Al}$ respecto, las esterasas producidas por bacterias halotolerantes son candidatas idóneas, por su termoestabilidad y actividad en solventes orgánicos, para la biosíntesis de nuevos compuestos en procesos industriales eficientes ${ }^{(16-18)}$.

La capacidad de hidrólisis y la frecuencia de uso de un sustrato $\mathrm{u}$ otro dependen de la procedencia del agua y de sus propiedades fisicoquímicas tales como temperatura, $\mathrm{pH}$, sales minerales, nutrientes ${ }^{(4-7)}$. Así, sólo una bacteria degradó almidón y otra lactosa, de ello se puede inferir que la mayoría de microorganismos aislados pertenecen a especies o cepas nuevas.

Al respecto, Margesin (3) y Galinski (1) han descrito que los perfiles hidrolíticos de las bacterias halotolerantes son variados y disímiles entre sí; es por ello que existen al menos 6 perfiles hidrolíticos en los microorganismos aislados, característica de gran interés en procesos industriales, dado que se pueden utilizar diferentes fuentes de carbono para su cultivo ${ }^{(1,3)}$.

Entre las 14 bacterias halotolerantes procedentes de aguas termales de Tarapoto existen al menos seis especiesocepas según lascaracterísticas bacteriológicas y el análisis de los perfiles de hidrólisis de sustratos comunes. Las bacterias aisladas constituyen fuentes nativas potenciales para la degradación y la síntesis de nuevos compuestos en un contexto ambiental limpio y sostenible.

\section{CONCLUSIÓN}

De las aguas termales de Tarapoto se aislaron 14 bacterias halotolerantes de aguas termales, la mayoría son Gram negativas, móviles, gomosas, crecen a $37^{\circ} \mathrm{C}, \mathrm{pH}$ 6,o y producen estearasas y amilasas que hidrolizan tween 8o y almidón, respectivamente; ninguna degrada carboximetilcelulosa.

\section{REFERENCIAS BIBLIOGRÁFICAS}

1. Galinski EA, Tindall BJ. Biotechnological prospects for halophiles and halotolerant microorganisms. In: 
Molecular biology and biotechnology of extremophiles. Blackie. Glasgow, 1992. p 76-114.

2. Cowan ST, Steel LJ. Manual for the identification of medical bacteria. $3^{\text {a }}$ ed. Cambridge University Press. UK, 1993.

3. Margesin R, Schinner F. Potential of halotolerant and halophilic microorganisms for biotechnology. Extremophiles 2001; 5(2): 73-83.

4. Schmidt H. Avances en ciencias y tecnología de los alimentos. Alfabet Impresora. Santiago de Chile, 1981.

5. Miller SL, Lazcano A. The origin of life: Did it occur at high temperatures?. J Mol Evol 1995; 41: 689-92.

6. Mosso MA, De La Rosa MC, Vivar MC. Microbiología del manantial Hervideros del Balneario de Cofrentes. An Real Acad Farm 1998; 64(Extr): 53-63.

7. Madigan M, Martinko J, Parker J. Brock J. Biología de los microorganismos. Prentice Hall. Madrid, 1997.

8. Ventosa A, Nieto JJ, Oren A. Biology of moderately halophilic aerobic bacteria. Microbiology and Molecular Biology Reviews 1998; 62(2): 504-44.

9. Hough D, Danson M. Extremozymes. Current Opinion in Chemical Biology 1999; 3(1): 39-46.

10. Sánchez-Porro C, Martín S, Mellado E, Ventosa A. Diversity of moderately halophilic bacteria producing extracellular hydrolytic enzymes. J Appl Microbiol 2003; 94(2): 295-300.

11. Silva AS. Bacilos gramnegativos no fermentadores. En: Procedimientos y técnicas de Laboratorio. Lobos $\mathrm{H}$, García J, eds. Universidad de Chile. Santiago de Chile, 1983. p 39-50.

12. Lévêque E, Janeček Š, Haye B, Belarbi A. Thermophilic archaeal amylolytic enzymes. Enzyme and Microbial Technology 2000; 26: 3-14.
13. Pachon L, Posada Y. Cuantificación de poblaciones anaerobias aminoacidolíticas y aminolíticas de un yacimiento termal de Palpa, Boyacá. Microbiología Industrial. Pontificia Universidad Javeriana. Facultad de Ciencias. Departamento de Microbiología. Unidad de Saneamiento y Biotecnología Ambiental (USBA). Bogotá. D.C., 2003.

14. Lee C-W, Ng A Y-F, Narayanan K, Sim E U-H, Ng C-C. Aislamiento y caracterización de bacterias cultivables de aguas costeras tropicales. Ciencias Marinas 2009; 35(2): 153-67.

15. ZoBell CE. Marine Microbiology. Chronica Botanica Company. Waltham MA. 1946.

16. Von Riesen VL. Convenient, simplified preparation of less commonly used media. J Clin Microbiol 1975; 2(6): 554-5.

17. Sierra G. A simple method for the detection of lipolytic activity of micro-organisms and some observations on the influence of the contact between cells and fatty substrates. Antonie van Leeuwenhoek 1957; 23(1): 15-22.

18. Sharma R, Chisti Y, Banerjee UC. Production, purification, characterization and applications of lipases. Biotechnology Advances 2001; 19(8): 627-62.

Manuscrito recibido el: 02/02/2013

Aceptado para su publicación el: 27/03/2013

\section{Correspondencia:}

Nombre: Jackelyn Borja

Dirección: Laboratorio de Biología Molecular, Facultad deFarmaciay Bioquímica-UNMSM, Lima 1- Perú. e-mail: jackelyn@gmail.com 